\title{
Hydroboration Copolymerization of Dienes and Dicyano Compounds with Thexylborane
}

\author{
Yoshiki Chujo,* Masao Morimoto, and Ikuyoshi Tomita** \\ Division of Polymer Chemistry, Graduate School of Engineering, \\ Kyoto University, Yoshida, Sakyo-ku, Kyoto 606-01, Japan
}

(Received August 16, 1994)

\begin{abstract}
We describe here the synthesis of boron-containing copolymers having two different segments of organoboron and cyclodiborazane units by the combination of hydroboration polymerization of dienes and that of dicyano compounds with thexylborane. While an organoboron polymer from thexylborane and diene has no UV absorption, the reaction mixture of thexylborane, diene and dicyano compound gave the polymer which had the peak top molecular weight around 9000 in GPC detected by UV. This result indicates that the polymer obtained from these three monomers might be the copolymer having two segments. The composition of two segments in copolymer was determined by ${ }^{1} \mathrm{H}$ NMR, and could be easily controlled by the feed ratio of dienes and dicyano compounds. From the results of air-bubbling experiments, the copolymers were found to have block-type structures. Various dienes and various dicyano compounds were used in this hydroboration copolymerization with thexylborane to produce the corresponding boron-containing copolymers.
\end{abstract}

KEY WORDS Hydroboration Polymerization / Diene / Dicyano Compounds / Thexylborane / Organoboron Polymers / Poly(cyclodiborazane)s / Block Copolymers /

Recently, we have explored hydroboration polymerization of dienes with monoalkylborane (Scheme 1) as a novel methodology for the preparation of organoboron polymers. ${ }^{1}$ The polymers obtained have a new structure consisting of carbon-boron bonds in the main chain and can be used as a novel type of reactive polymers. Versatile reactions of organoboron polymers have been demonstrated to give polymers having various functional groups such as alcohol, ketone, and nitrile. ${ }^{2}$

On the other hand, we also reported hydro-
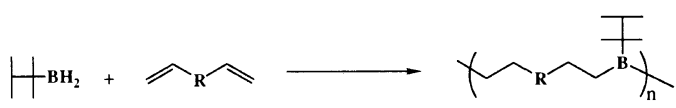

Scheme 1. boration polymerization between dicyano compounds and monoalkylborane (Scheme 2) to give poly(cyclodiborazane)s. ${ }^{3}$ This polymerization includes the dimerization of iminoborane species to afford the boronnitrogen four-membered rings, "cyclodiborazane", as a key step. The polymers obtained were very stable toward air and moisture, while organoboron polymers prepared from dienes were unstable in air to decompose.

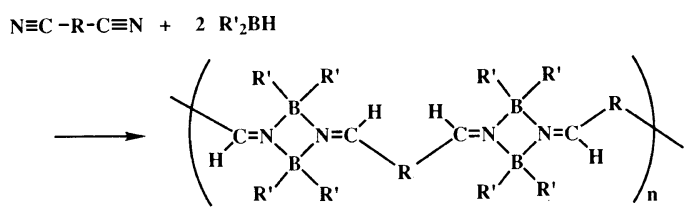

Scheme 2.

\footnotetext{
* To whom all correspondence should be addressed.

** Present address: Research Laboratory of Resources Utilization, Tokyo Institute of Technology, Nagatsuda, Midori-ku, Yokohama 227, Japan.
} 
Thus, it should be attractive to explore the preparation of copolymers having two different boron-containing moieties, trialkylborane and cyclodiborazane units, in the main chain. This paper describes the synthesis of such copolymers by the reactions of dienes and dicyano compounds with thexylborane.

\section{RESULTS AND DISCUSSION}

The copolymerization of dienes and dicyano compounds with thexylborane described here might include hydroboration of thexylborane to olefins and nitriles and dimerization of in-situ generated iminoborane species. As a result, the organoboron copolymers obtained consist of two segments in the main chain as illustrated in Scheme 3.

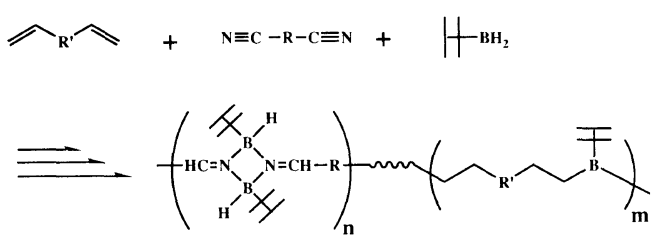

Scheme 3.

Table I. Dependence of molecular weight on the temperature and reaction time in hydroboration copolymerization of 1,2 , and $3^{\mathrm{a}}$

\begin{tabular}{|c|c|c|c|c|c|}
\hline \multirow{2}{*}{ Run } & Temp & Time & \multirow{2}{*}{$\bar{M}_{n}^{\mathrm{b}}$} & \multirow{2}{*}{$\bar{M}_{w}{ }^{b}$} & \multirow{2}{*}{$M P^{\mathrm{c}}$} \\
\hline & ${ }^{\circ} \mathrm{C}$ & $\mathrm{h}$ & & & \\
\hline 1 & r.t. $^{\text {d }}$ & 24 & 2100 & 3400 & 3650 \\
\hline 2 & & 71 & 2110 & 3320 & 4300 \\
\hline 3 & 30 & 24 & 2030 & 4140 & 1560 \\
\hline 4 & & 36 & 2480 & 5380 & 6310 \\
\hline 5 & 40 & 12 & 2520 & 6330 & 6990 \\
\hline 6 & & 24 & 2900 & 9280 & 6710 \\
\hline 7 & 50 & 5 & 2340 & 5530 & 5050 \\
\hline 8 & & 11 & 2030 & 6950 & 3300 \\
\hline 9 & & 23 & 2050 & 28100 & 1470 \\
\hline
\end{tabular}

a Polymerizations were carried out by adding 3 (3 eq) to the $1.9 \mathrm{M}$ THF solution of 1 (1 eq) and 2 (1 eq).

b GPC (dry THF), polystyrene standards.

c Peak top molecular weight.

d The addition of thexylborane was carried out at $0^{\circ} \mathrm{C}$.
Hydroboration Copolymerization of 1,7-Octadiene (1) and Pimelonitrile (2) with Thexylborane (3)

First, the reactions of 1,7-octadiene (1) and pimelonitrile (2) with thexylborane (3) were carried out at various temperatures, e.g., room temperature, 30,40 , and $50^{\circ} \mathrm{C}$. These samples were subjected directly to GPC analyses. The results are listed in Table I, from which the best condition for this polymerization was found to be at $40^{\circ} \mathrm{C}$ and for $24 \mathrm{~h}$. When the reaction was carried out at room temperature or at $30^{\circ} \mathrm{C}$, the polymerization proceeded very slowly. The polymerization at $50^{\circ} \mathrm{C}$ caused the addition of unreacted 3 to monomeric or dimeric iminoboranes, and as a result, a gelation was observed or the polymer obtained had lower molecular weight.

Generally, stoichiometry is quite important for polyaddition reaction. ${ }^{4}$ While an equimolar amount of 3 is required in the polymerization with 1, two equivalents of 3 are used in the polymerization with 2 . To check this, the reactions of 1 and 2 with 3 were carried out in THF at $40^{\circ} \mathrm{C}$ for $24 \mathrm{~h}$ at various feed ratios. These results are shown in Table II. The reactions using less amount of $\mathbf{3}$ than theoretical one gave low molecular weight oligomers (runs 1 and 2). In these cases, some of cyano groups in 2 should remain unreacted since the reaction of $\mathbf{2}$ with $\mathbf{3}$ proceeds much slower than that of 1 with 3 . When a theoretical amount of $\mathbf{3}$ was

Table II. Dependence of molecular weight on the feed ratio of the monomers in hydroboration copolymerization $^{\mathrm{a}}$

\begin{tabular}{ccccccr}
\hline Run & $\mathbf{1}$ & $\mathbf{2}$ & $\mathbf{3}$ & $\bar{M}_{n}{ }^{\mathrm{b}}$ & $\bar{M}_{\boldsymbol{w}}{ }^{\mathrm{b}}$ & $M P^{\mathrm{c}}$ \\
\hline 1 & 1 & 1 & 1 & 1560 & 9990 & 630 \\
2 & 1 & 1 & 2 & 2220 & 6670 & 1470 \\
3 & 1 & 1 & 3 & 2900 & 9280 & 6710 \\
4 & 2 & 1 & 4 & 3090 & 9690 & 9870 \\
5 & 1 & 2 & 5 & 1340 & 2260 & 1380 \\
\hline
\end{tabular}

a Polymerizations were carried out by addition of $\mathbf{3}$ to the $1.9 \mathrm{M}$ THF solution of 1 and 2 .

b GPC (dry THF), polystyrene standards.

c Peak top molecular weight. 
Table III. Dependence of molecular weight on the concentration of monomers in hydroboration copolymerization of 1,2 , and $3^{a}$

\begin{tabular}{ccccc}
\hline Run & $\begin{array}{c}\text { Concentration } \\
\text { mol 1 }\end{array}$ & $\bar{M}_{n}{ }^{\mathrm{c}}$ & $\bar{M}_{\boldsymbol{w}}{ }^{\mathrm{c}}$ & $\boldsymbol{M} \boldsymbol{P}^{\mathrm{d}}$ \\
\hline 1 & 1.2 & 2110 & 6100 & 1560 \\
2 & 1.9 & 3090 & 9690 & 9870 \\
3 & 3.1 & 1520 & 5870 & 1590 \\
4 & $9.2^{\mathrm{e}}$ & 1940 & 7340 & 1590 \\
\hline
\end{tabular}

a Polymerizations were carried out in THF at $40^{\circ} \mathrm{C}$ for $24 \mathrm{~h}$.

${ }^{\mathrm{b}}[\mathrm{M}]_{0}=[1]_{0}+[2]_{0}+[3]_{0}$.

c GPC (dry THF), polystyrene standards.

d Peak top molecular weight.

c Polymerization was carried out in bulk.

used (runs 3, 4, and 5), the reaction in the feed ratio of $[1]_{0} /[2]_{0} /[3]_{0}=2 / 1 / 4$ gave the highest molecular weight polymer (run 4). On the other hand, when the ratio of $\mathbf{2}$ to $\mathbf{1}$ was two (run 5), the molecular weight of the polymer obtained was very low due to the increase in iminoborane contents in the resulting copolymer.

Initial total monomer concentration, $[\mathrm{M}]_{0}$ $\left(=[1]_{0}+[2]_{0}+[3]_{0}\right)$, was examined in the reaction under the best condition as mentioned above, at $40^{\circ} \mathrm{C}$ for $24 \mathrm{~h}$ and $[1]_{0} /[2]_{0} /[3]_{0}=$ $2 / 1 / 4$, in four designated concentrations of $[\mathrm{M}]_{0}=1.2,1.9,3.1$ or $9.2 \mathrm{moll}^{-1}$, respectively. The results are summarized in Table III, from which the initial concentration of $1.9 \mathrm{moll}^{-1}$ was found to be the most desirable (run 2). The key propagation step of this copolymerization should be the dimerization of iminoborane species generated in the reactions of 2 with 3 . This means that the monomer concentration has an influence on the rate of this polymerization. Accordingly, when the concentration was $1.2 \mathrm{moll}^{-1}$ (run 1), it was too dilute for dimerization of iminoborane species. On the other hand, when the concentration was far from $1.9 \mathrm{moll}^{-1}$ (run 4), the additions of unreacted 3 to monomeric or dimeric iminoboranes might take place, which prevent the formation of cyclodiborazane backbone. As

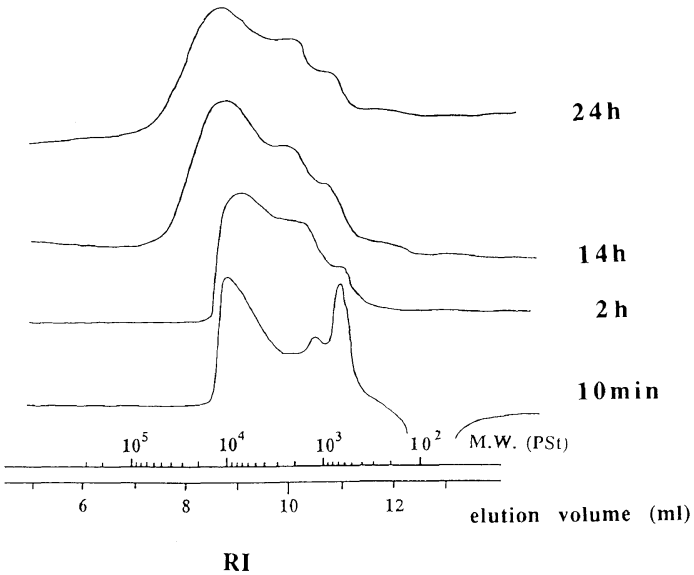

Figure 1. GPC traces of hydroboration copolymerization of 1 and 2 with 3 at $40^{\circ} \mathrm{C}$ after $10 \mathrm{~min}, 2 \mathrm{~h}, 14 \mathrm{~h}$, and $24 \mathrm{~h}$.

a result, the polymer obtained under this condition had low molecular weight.

The polymerization of 1 and 2 with 3 $\left([1]_{0} /[2]_{0} /[3]_{0}=2 / 1 / 4\right)$ at $40^{\circ} \mathrm{C}$ was monitored by GPC as illustrated in Figure 1 . After $10 \mathrm{~min}$, two main peaks were observed around 10000 and 600 calculated by using polystyrene standards. After $2 \mathrm{~h}$, these peaks became broader. The molecular weight of the polymer obtained reached to a maximum after $14 \mathrm{~h}$. The IR spectra after $10 \mathrm{~min}, 2 \mathrm{~h}$ and $24 \mathrm{~h}$, respectively, are shown in Figure 2. A strong absorption band around $2365 \mathrm{~cm}^{-1}$ which is characteristic of B-H stretching vibrațion of thexylborane decreased, while a peak around $1670 \mathrm{~cm}^{-1}$ assignable to $\mathrm{C}=\mathrm{N}$ stretching band increased. After $24 \mathrm{~h}$, however, there still remained the peak around $2365 \mathrm{~cm}^{-1}$ which corresponds to $\mathrm{B}-\mathrm{H}$ stretching vibration in cyclodiborazane backbone.

It was confirmed by GPC analyses using UV and RI detectors that the polymer obtained was an organoboron copolymer. While an organoboron polymer prepared from 1 and 3 has no UV absorption, the polymer from 2 and 3 has the peak top molecular weight around 1000 in GPC detected by UV (Figure 3). On the other hand, the reaction mixture of $1+2+3$ 


\section{Hydroboration Copolymerization}
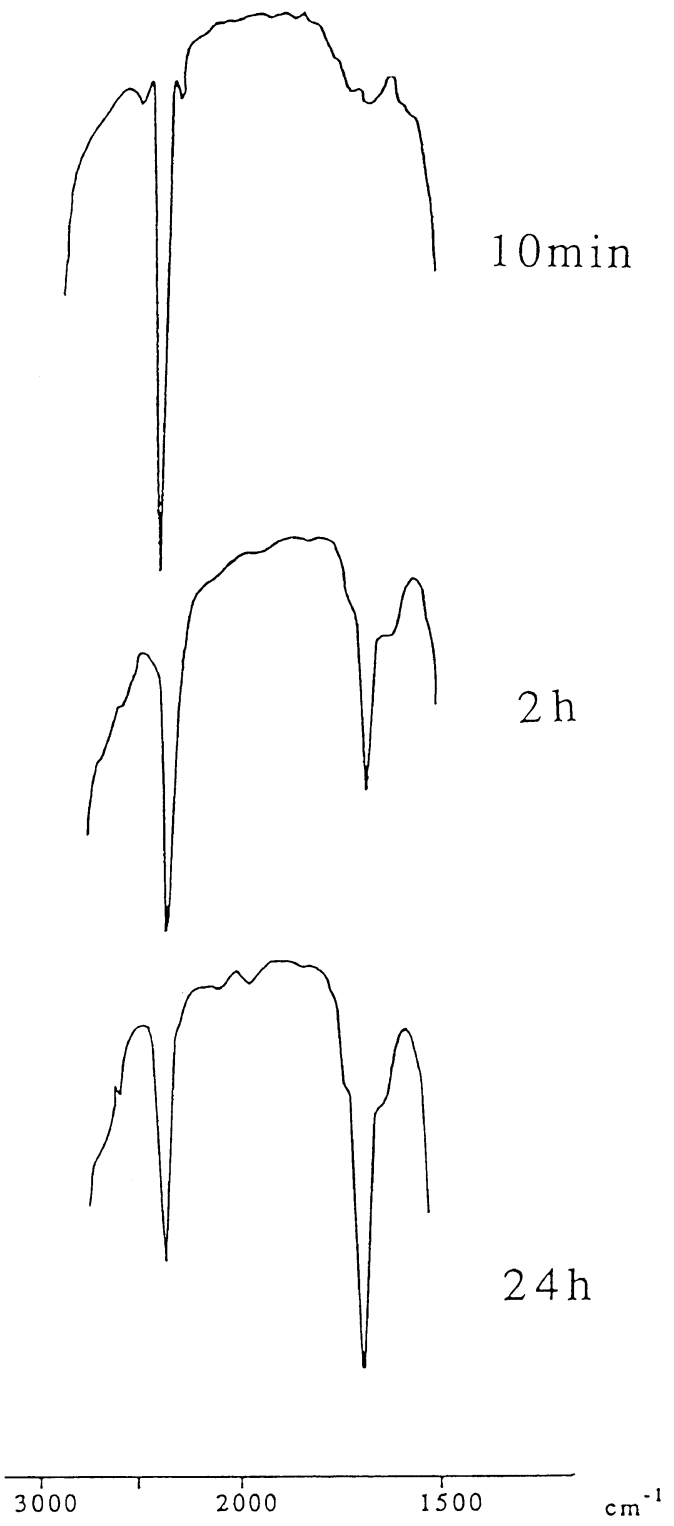

Figure 2. IR spectra of the reaction mixture in hydroboration copolymerization of 1 and 2 with 3 after $10 \mathrm{~min}$, $2 \mathrm{~h}$, and $24 \mathrm{~h}$.

gave the polymer having the peak top molecular weight around 9000 , which was observed by using both UV and RI detectors. These results indicate that the polymer obtained from $1+2+3$ might be the copolymer having two segments.
The structure of the copolymer obtained was confirmed by ${ }^{1} \mathrm{H},{ }^{11} \mathrm{~B}$ NMR, and IR spectra, respectively. In the ${ }^{1} \mathrm{H}$ NMR, a signal assignable to $\mathrm{CH}=\mathrm{N}$ of dimeric iminoboranes was observed around $7.6 \mathrm{ppm}$ and a signal for thexyl protons was found around $0.8 \mathrm{ppm}$. In the ${ }^{11} \mathrm{~B}$ NMR spectrum, there were two strong absorptions around 31.7 and $2.8 \mathrm{ppm}$ corresponding to three- and four-coordinated boron atoms, respectively. In the IR spectrum, two peaks were observed around 2367 and 1673 $\mathrm{cm}^{-1}$ as mentioned above.

The composition of the isolated copolymer was determined by ${ }^{1} \mathrm{H}$ NMR. When an equimolar amount of $\mathbf{1}$ to $\mathbf{2}$ was used (Table II, run 3 ), the resulting copolymer was found to consist of only $27 \%$ cyclodiborazane units. In the case of the sample of run 5 in Table II $\left([1]_{0} /[2]_{0}=1 / 2\right)$, comparable contents of two segments (45\% cyclodiborazane) were observed in the resulting copolymer. The isolated copolymer in the case of run 4 consisted of $17 \%$ cyclodiborazane units. From these results, it could be explained that the reactivity of 1 was higher than that of $\mathbf{2}$ or that a low molecular weight poly(cyclodiborazane)-rich copolymer was removed during the isolation procedure.

\section{Stability of Organoboron Copolymer}

According to the previous reports, ${ }^{1}$ the organoboron polymers obtained from 1 and 3 were unstable against air, while the polymers from 2 and 3 were stable toward air. The organoboron copolymers obtained in the present study may be unstable against air due to their organoboron segments. As shown in Figure 4, the decomposition of the copolymer in air was monitored by GPC after air-bubbling into a THF solution of the copolymer, which was prepared by the reaction of 1 and 2 with $3\left([1]_{0} /[2]_{0} /[3]_{0}=1 / 1 / 3\right)$. After $1 \mathrm{~h}$ air-bubbling, the peak in GPC moved to the low molecular weight region. In ${ }^{1} \mathrm{H}$ NMR spectrum of the product, two signals assignable to the methylene protons adjacent to oxygen atom 


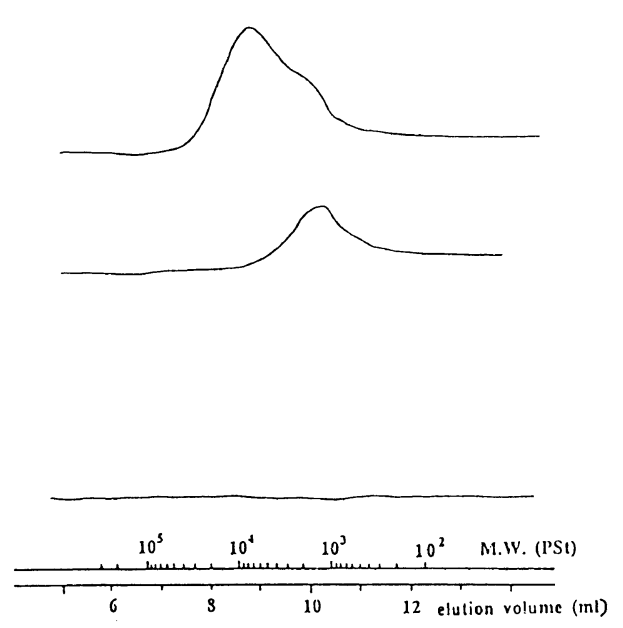

\section{UV}

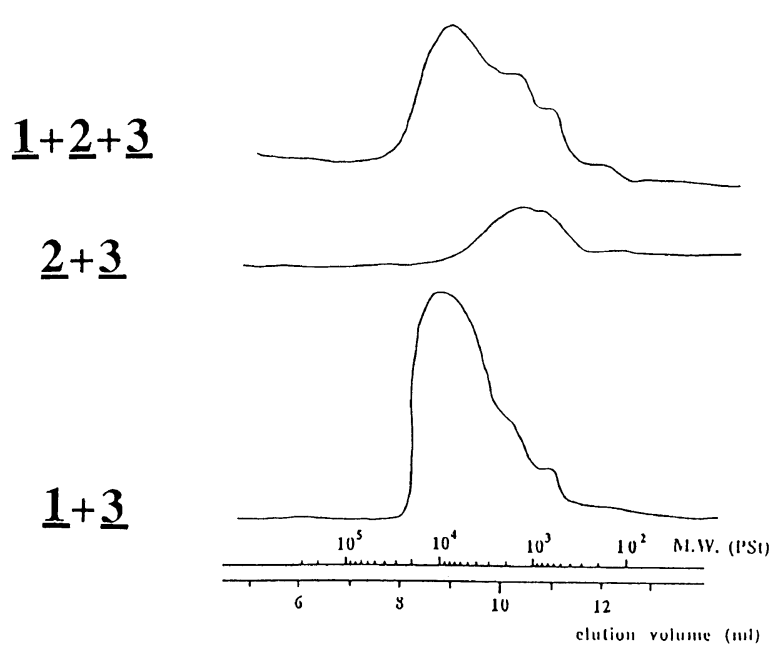

RI

Figure 3. GPC traces of the reaction mixtures of $1+3,2+3$, and $1+2+3$.

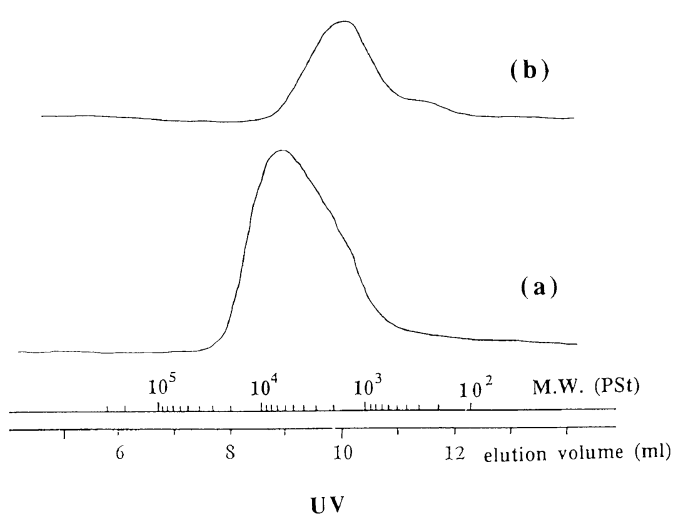

Figure 4. GPC traces of (a) the copolymer prepared from 1,2 and 3 and (b) that after air-bubbling for $1 \mathrm{~h}$.

and to the methine protons of dimeric iminoboranes were observed around 3.7 and $7.6 \mathrm{ppm}$, respectively. These results indicate that air-bubbling resulted in the oxidative scission of C-B bonds in organoboron moieties without decomposition of the cyclodiborazane units. However, the complete decomposition of the copolymer was not observed even after $24 \mathrm{~h}$ air-bubbling. This means that the copolymer consists of air-stable poly(cyclodiborazane) segments.

\section{Mixing of Organoboron Polymer and Poly- (cyclodiborazane)}

A solution of the polymer obtained from $1+3$ and that from $2+3$ were mixed under nitrogen. After $24 \mathrm{~h}$ at $40^{\circ} \mathrm{C}$, GPC measurement of the resulting mixture was compared with that of each original polymer solution. The result is illustrated in Figure 5. The peak of the mixture of $\mathbf{1}+3$ and $2+3$ was not the sum of the peak of $1+3$ and that of $2+3$, but shifted to higher molecular weight region. This behavior can be explained by the formation of a block copolymer after mixing. In other words, the end groups of two boron-containing polymers, $\mathbf{1}+\mathbf{3}$ and $\mathbf{2}+\mathbf{3}$, might remain reactive even after each polymerization. The decomposition of the resulting copolymer against air was monitored by GPC after air-bubbling into a THF solution of the copolymer. The same results as the polymer prepared from $\mathbf{1}+\mathbf{2}+\mathbf{3}$ were observed.

\section{Hydroboration Copolymerization of Various}

Dienes and 2 with 3

The hydroboration polymerizations of various dienes and 2 with 3 were carried out in THF at $40^{\circ} \mathrm{C}$ for $24 \mathrm{~h}$ ([Diene $]_{0} /[2]_{0} /[3]_{0}=$ 


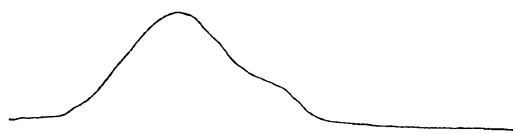

Mixture
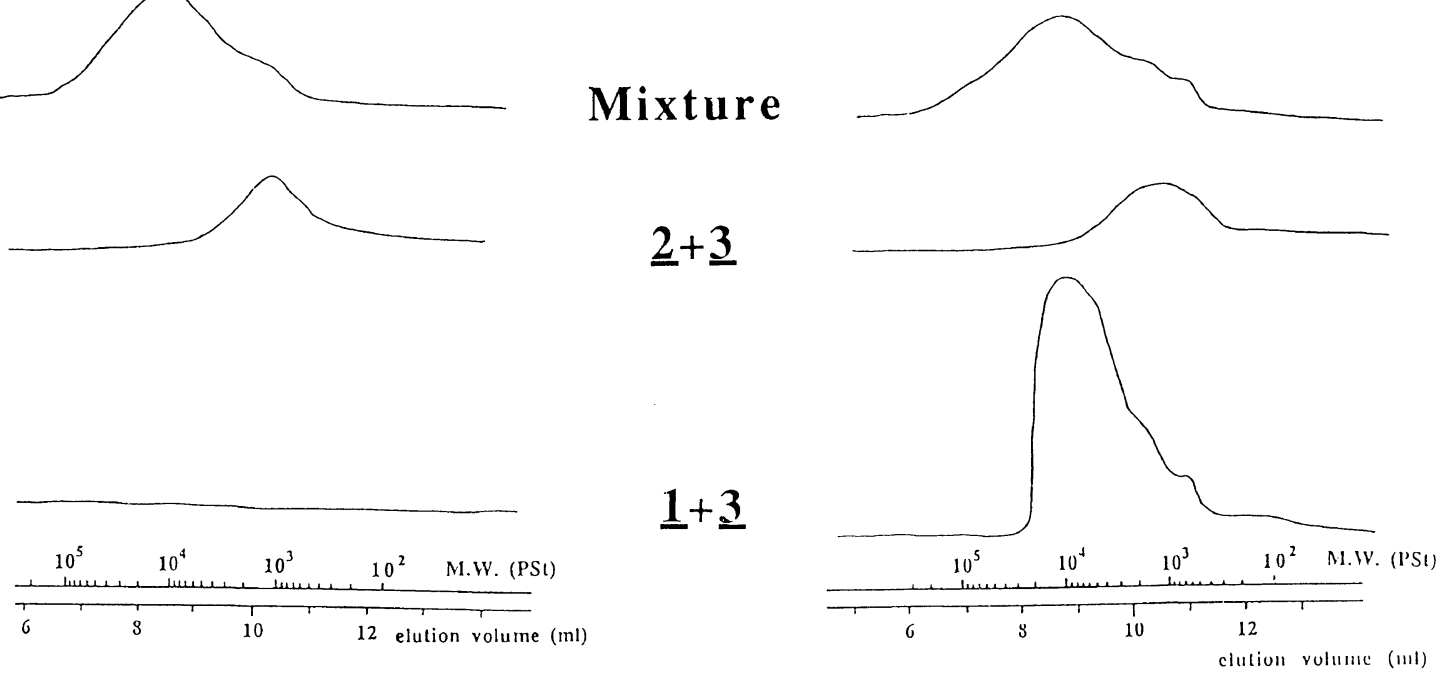

$\mathbf{U V}$

\section{RI}

Figure 5. GPC traces of the polymer prepared from $1+3$, that from $2+3$, and a mixture of these polymers.

Table IV. Hydroboration copolymerization of various dienes and 2 with $3^{\text {a }}$

\begin{tabular}{|c|c|c|c|c|c|}
\hline Run & Diene & Yield $/ \%$ b & $\begin{array}{l}\text { Polymer content } \\
\text { (Diene/Dicyano) }\end{array}$ & $\bar{M}_{n}$ & $\bar{M}_{w}$ \\
\hline 1 & & 74 & $73 / 27$ & 2550 & 4210 \\
\hline 2 & & 72 & $65 / 35$ & 1940 & 3180 \\
\hline 3 & & 50 & $68 / 32$ & 4120 & 12970 \\
\hline 4 & & 61 & $67 / 33$ & 1540 & 2340 \\
\hline
\end{tabular}

a Polymerizations were carried out in THF at $40^{\circ} \mathrm{C}$ for $24 \mathrm{~h}$.

b Isolated yield after reprecipitation into $\mathrm{MeOH}$.

c Determined by ${ }^{1} \mathrm{H}$ NMR.

2/1/4). As shown in Table IV, the reactions of various dienes such as bis(allyl ether)s (runs 2 and 3) and aromatic diene (run 4), and 2 with 3 afforded the corresponding copolymers. In all cases, the major segments were those from dienes similarly to the case of $\mathbf{1}$.

\section{Hydroboration Copolymerization of Various} Dicyano Compounds and $\mathbf{1}$ with $\mathbf{3}$

The reactions of $\mathbf{1}$ and various dicyano compounds with 3 were carried out in THF. The results are listed in Table V. Even in the cases using solid aromatic dicyano compounds (runs 2 and 3), the reactions proceeded in homogeneous solutions and gave the corresponding copolymers. In IR spectrum of each copolymer, a sharp absorption of $\mathrm{C}=\mathrm{N}$ stretching vibration was observed around $1645 \mathrm{~cm}^{-1}$. In conclusion, various boroncontaining copolymers can be produced by 
Table V. Hydroboration copolymerization of various dicyano compounds and 1 with $3^{\mathbf{a}}$

\begin{tabular}{cccccc}
\hline Run & Dicyano compound & Yield $/ \%{ }^{\mathrm{b}}$ & $\begin{array}{c}\text { Polymer content } \\
\text { (Diene/Dicyano) }\end{array}$ & $\bar{M}_{n}$ & $\bar{M}_{w}$ \\
\hline 1 & $\mathrm{NC}\left(\mathrm{CH}_{2}\right)_{5} \mathrm{CN}$ & 74 & $73 / 27$ & 2550 & 4210 \\
2 & & 47 & $67 / 33$ & 2390 & 3780 \\
3 & & 43 & $66 / 34$ & 1950 & 2710 \\
\hline
\end{tabular}

a Polymerizations were carried out in THF at $40^{\circ} \mathrm{C}$ for $24 \mathrm{~h}$.

b Isolated yield after reprecipitation into $\mathrm{MeOH}$.

c Determined by ${ }^{1} \mathrm{H}$ NMR.

hydroboration copolymerization of various dienes and dicyano compounds with 3 .

\section{EXPERIMENTAL}

\section{Materials and Instruments}

All dienes and $\mathbf{2}$ were purified by distillation. 3 was prepared by the reaction of boranedimethyl sulfide with 2,3-dimethyl-2-butene and was purified by distillation, according to the reported method. ${ }^{5}$ Bis(allyl ether)s of 1,4-butanediol and triethylene glycol were prepared from the corresponding glycols and allyl bromide and purified by distillation. Isophthalonitrile was purified by sublimation. Tetrahydrofuran was dried over sodium and distilled before use.

${ }^{1} \mathrm{H}$ and ${ }^{11} \mathrm{~B}$ NMR spectra were recorded in $\mathrm{CDCl}_{3}$ on a JEOL JNM-GX400 or a Hitachi R-600 instrument. FT-IR spectrum was obtained on a Perkin Elmer 1600 spectrometer. Gel permeation chromatographic analysis was carried out on a Tosoh HLC-8020 (TSK gel G4000) by using dried THF as eluent after calibration with standard polystyrene samples.

\section{Hydroboration Copolymerization of $\mathbf{1}$ and $\mathbf{2}$ with 3}

A typical procedure is described as follows. To a $1.1-\mathrm{ml}$ tetrahydrofuran (THF) solution of $1(55.1 \mathrm{mg}, 0.500 \mathrm{mmol})$ and $2(61.7 \mathrm{mg}$, $0.505 \mathrm{mmol}), 3(0.20 \mathrm{ml}, 1.50 \mathrm{mmol})$ was added slowly $(200 \mu \mathrm{l} / \mathrm{min})$ by a microfeeder in the feed ratio of $[1]_{0} /[2]_{0} /[3]_{0}=2 / 1 / 4$ at $40^{\circ} \mathrm{C}$. The initial total monomer concentration was $1.87 \mathrm{moll}^{-1}$. The solution was stirred at that temperature for $24 \mathrm{~h}$ and was subjected directly to GPC analysis. The polymer obtained was precipitated into dried $\mathrm{MeOH}$ under nitrogen followed by drying under vacuum. The product was a white gum. Yield was $0.195 \mathrm{~g}(74 \%) .{ }^{1} \mathrm{H}$ $\operatorname{NMR}\left(\delta, \mathrm{CDCl}_{3}\right): 0.52-1.08 \quad\left(\mathrm{CH}_{3}, \mathrm{~m}\right)$, $1.08-2.06\left(\mathrm{CH}_{2}, \mathrm{CH}, \mathrm{m}\right), 2.06-2.45(\mathrm{~N}=$ $\left.\mathrm{C}-\mathrm{CH}_{2}, \mathrm{~m}\right)$, and $7.58(\mathrm{~N}=\mathrm{CH}, \mathrm{br}, \mathrm{s})$. IR (film): 2933, 2855, 2367, 1673, 1467, 1367, 1262, 1095, $1067,912,801$, and $734 \mathrm{~cm}^{-1}$.

\section{Hydroboration Copolymerization of Bis(allyl ether) of 1,4-Butanediol and 2 with 3}

In a similar method to that mentioned above, the corresponding polymer was obtained from bis(allyl ether) of 1,4-butanediol, 2 and 3. Yield was $72 \% .{ }^{1} \mathrm{H}$ NMR $\left(\delta, \mathrm{CDCl}_{3}\right): 0.51-1.43$ $\left(\mathrm{CH}_{3}, \mathrm{~m}\right), 1.43-2.35\left(\mathrm{CH}_{2}, \mathrm{CH}, \mathrm{m}\right), 2.35-$ $3.01\left(\mathrm{~N}=\mathrm{C}-\mathrm{CH}_{2}, \mathrm{~m}\right), 3.28-4.30\left(\mathrm{OCH}_{2}, \mathrm{~m}\right)$, and $7.92(\mathrm{~N}=\mathrm{CH}, \mathrm{br}, \mathrm{s})$. IR (film): 2933, 2867, $2367,1673,1467,1373,1262,1101,912,801$, and $734 \mathrm{~cm}^{-1}$.

\section{Hydroboration Copolymerization of Bis(allyl ether) of Triethylene Glycol and $\mathbf{2}$ with $\mathbf{3}$ \\ The polymer from bis(allyl ether) of triethylene glycol, 2 and 3 was obtained in $50 \%$ yield. ${ }^{1} \mathrm{H}$ NMR $\left(\delta, \mathrm{CDCl}_{3}\right): 0.22-1.10\left(\mathrm{CH}_{3}\right.$,}


$\mathrm{m}), \quad 1.10-2.01\left(\mathrm{CH}_{2}, \mathrm{CH}, \mathrm{m}\right), 2.01-2.68$ $\left(\mathrm{N}=\mathrm{C}-\mathrm{CH}_{2}, \mathrm{~m}\right), 2.95-3.88\left(\mathrm{OCH}_{2}, \mathrm{~m}\right)$, and 7.59 ( $\mathrm{N}=\mathrm{CH}$, br, s). IR (film): 2933, 2867, 2367, 1673, 1467, 1373, 1262, 1095, 917, 801, and $734 \mathrm{~cm}^{-1}$.

Hydroboration Copolymerization of p-Divinylbenzene and $\mathbf{2}$ with $\mathbf{3}$

In a similar manner to that mentioned above, the corresponding polymer was obtained from p-divinylbenzene, 2 and 3 in $61 \%$ yield. ${ }^{1} \mathrm{H}$ NMR $\left(\delta, \mathrm{CDCl}_{3}\right): 0.47-1.08\left(\mathrm{CH}_{3}, \mathrm{~m}\right)$, $1.08-2.05\left(\mathrm{CH}_{2}, \mathrm{CH}, \mathrm{m}\right), 2.05-3.03(\mathrm{~N}=$ $\left.\mathrm{C}-\mathrm{CH}_{2}, \mathrm{~m}\right), 6.77-7.30(\mathrm{ArH}, \mathrm{m})$, and 7.53 ( $\mathrm{N}=\mathrm{CH}$, br, s). IR (film): 2954, 2867, 2365, $1676,1507,1464,1365,1262,1060,908,804$, and $733 \mathrm{~cm}^{-1}$.

Hydroboration Copolymerization of 1,5-Bis(4,4'-cyanophenoxy)pentane and 1 with 3

Yield of the polymer prepared from 1,5bis $\left(4,4^{\prime}\right.$-cyanophenoxy)pentane, 1 and 3 was $47 \% .{ }^{1} \mathrm{H}$ NMR $\left(\delta, \mathrm{CDCl}_{3}\right): 0.22-1.08\left(\mathrm{CH}_{3}\right.$, $\mathrm{m}), 1.08-1.52\left(\mathrm{CH}_{2}, \mathrm{CH}, \mathrm{m}\right), 1.52-2.36$ $\left(\mathrm{N}=\mathrm{C}-\mathrm{CH}_{2}, \mathrm{~m}\right), \quad 3.80-4.34 \quad\left(\mathrm{OCH}_{2}, \mathrm{~m}\right)$, 6.43-7.76 (ArH, $\mathrm{m})$, and $8.26(\mathrm{~N}=\mathrm{CH}, \mathrm{br}, \mathrm{s})$. IR (film): 2927, 2865, 2372, 1644, 1607, 1514, $1465,1366,1311,1255,1169,1064,910,830$, and $731 \mathrm{~cm}^{-1}$.

\section{Hydroboration Copolymerization of Isophthalo- nitrile and $\mathbf{1}$ with $\mathbf{3}$}

The polymer from isophthalonitrile, $\mathbf{1}$ and 3 was obtained in $43 \%$ yield. ${ }^{1} \mathrm{H} \operatorname{NMR}(\delta$, $\left.\mathrm{CDCl}_{3}\right): 0.41-1.02\left(\mathrm{CH}_{3}, \mathrm{~m}\right), 1.02-2.23$
$\left(\mathrm{CH}_{2}, \mathrm{CH}, \mathrm{m}\right), 7.14-8.20(\mathrm{ArH}, \mathrm{m})$, and 8.37 $(\mathrm{N}=\mathrm{CH}, \mathrm{br}, \mathrm{s})$. IR (film): 2927, 2865, 2372, $1650,1459,1366,1157,1095,910,805$, and $731 \mathrm{~cm}^{-1}$.

\section{REFERENCES}

1. a) Y. Chujo, I. Tomita, Y. Hashiguchi, H. Tanigawa, E. Ihara, and T. Saegusa, Macromolecules, 24, 345 (1991). b) Y. Chujo, I. Tomita, Y. Hashiguchi, and T. Saegusa, Macromolecules, 25, 33 (1992). c) Y. Chujo, I. Tomita, and T. Saegusa, Polym. Bull., 27, 375 (1992). d) Y. Chujo, I. Tomita, and T. Saegusa, Makromol. Chem., Macromol. Symp., 70/71, 47 (1993). e) Y. Chujo, N. Takizawa, and T. Sakurai, J. Chem. Soc., Chem. Commun., 227 (1994).

2. a) Y. Chujo, I. Tomita, N. Murata, H. Mauermann, and T. Saegusa, Macromolecules, 25, 27 (1992). b) Y. Chujo, I. Tomita, and T. Saegusa, Macromolecules, 25, 3005 (1992). c) Y. Chujo, I. Tomita, and T. Saegusa, Polym. Bull., 31, 547 (1993). d) Y. Chujo, I. Tomita, and T. Saegusa, Polym. Bull., 31, 553 (1993). e) Y. Chujo, I. Tomita, T. Asano, and T. Saegusa, Polym. J., 26, 85 (1994). f) Y. Chujo, I. Tomita, and T. Saegusa, Macromolecules, 27, 6714 (1994).

3. a) Y. Chujo, I. Tomita, Y. Hashiguchi, and T. Saegusa, Macromolecules, 24, 3010 (1991). b) Y. Chujo, I. Tomita, Y. Hashiguchi, and T. Saegusa, Polym. Bull., 25, 1 (1991). c) Y. Chujo, I. Tomita, and T. Saegusa, Polym. Bull., 26, 165 (1991). d) Y. Chujo, M. Morimoto, and I. Tomita, Polym. Bull., 29, 617 (1992). e) Y. Chujo, M. Morimoto, and I. Tomita, Polym. J., 25, 891 (1993). f) Y. Chujo, J. Macromol. Sci., Pure and Appl. Chem., A31, 1647 (1994).

4. D. H. Solomon, "Step-Growth Polymerization," Marcel Dekker Inc., New York, N.Y., 1972.

5. H. C. Brown, A. K. Mandal, and S. U. Kulkarni, $J$. Org. Chem., 42, 1392 (1977). 